American Journal of Applied Sciences 2 (5): 1008-1013, 2005

ISSN 1546-9239

(C) Science Publications, 2005

\title{
Improving the Gas Instantaneous Water Heaters Performances
}

\author{
Nasir Kloub \\ Al-Balqa Applied University, P.O. Box 861, Code 19110, Salt, Jordan
}

\begin{abstract}
This study presents a study of a theoretical and practical investigation of the gas Instantaneous (Tankless) water Heaters performance. The results allow us to obtain realistic values of the control system in the various capacities gaseous flowing water heaters. The objective of this work is to study the operation of the plans in the field of controlling and checking low capacity gaseous flowing water in order to choose the proper plan of the logical values and measures for these equipments that may be used in industrial conditions. Also results of the work proved to be accurate. A design of the control system was made. The results of the practical experiment of the control system were similar to the arithmetic results.
\end{abstract}

Key words: Gas Consumption, Water Heaters, Hydraulic Transformer

\section{INTRODUCTION}

Gas has long been recognized as the most efficient, reliable and economical way to heat water. Propane water heating systems offer several benefits: a continuous supply of hot water, low operating costs, minimal maintenance, high reliability and a proven long $\operatorname{life}^{[1,2]}$.

It's no secret that heating water is a significant portion of your overall energy budget in food service. An ample supply of hot water is required for routine kitchen needs, dishwashing, pot washing, general cleaning and any number of additional uses to maintain a high standard of sanitation. To serve these needs, gas is the only reasonable choice that delivers large quantities of hot water on a continuous basis. The instantaneous tankless water heater saves storage space and supplies hot water for immediate use by drawing water through the heater as you need it. Propane booster heaters are also available that help boost the temperature of general purpose water from $140^{\circ} \mathrm{F}$ to $180^{\circ} \mathrm{F}$. With recent technology improvements the gasfired booster water heater is one of the single best investments you can make for dishwashing sanitation. The propane will provide more hot water in less space, for less money and in less time than any comparable other unit. Tankless hot water heaters differ from their tank-type cousins in that they have no stored hot water. Tankless water heaters only heat water that is actually used. The most energy efficient tankless water heaters use either natural gas or propane (Fig. 1). The objective of this work is to study the operation of the plans in the field of controlling and checking low capacity gaseous flowing water in order to choose the proper plan of the logical values and measures for these equipments that may be used ${ }^{[3]}$. All the requirements of the theses system such as efficiency, safety of function, specialty in the design and conditions of use all were taken into consideration.

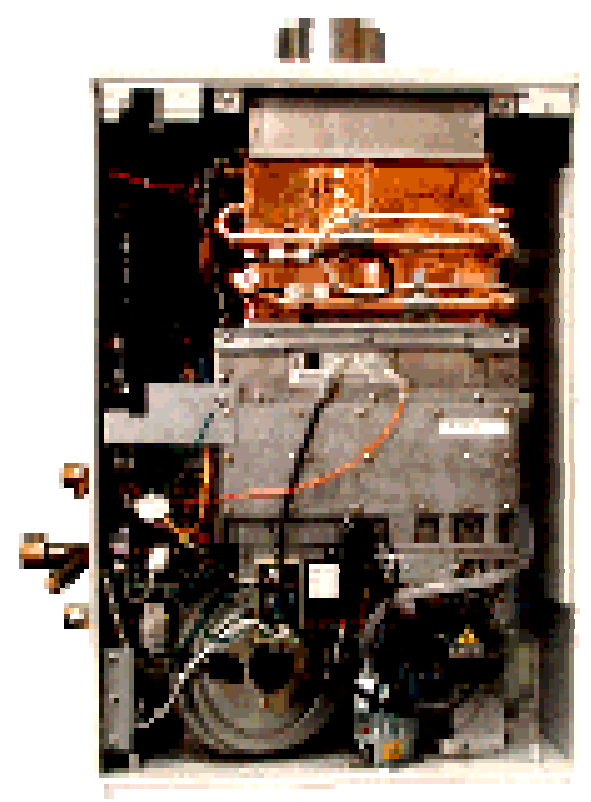

Fig. 1: The Tankless Gas Heaters

The results of this work, represented in the control system and the sets of measurements of this system, which can be used in various types of low capacity flow gas water heaters, will be used in manufacturing to provide the inhabitants with hot water for domestic uses.

\section{MATERIALS AND METHODS}

The study of the control system in the low capacity flow gas water heaters and the study of three available sketches of the automatic hydraulic transfer: The consecutive connection of the following elements or with transferring or side element which close the value opening (Fig. 2) an transferring (side) element which opens the value opening. The mathematical model for each of the above-mentioned sketches were made. 


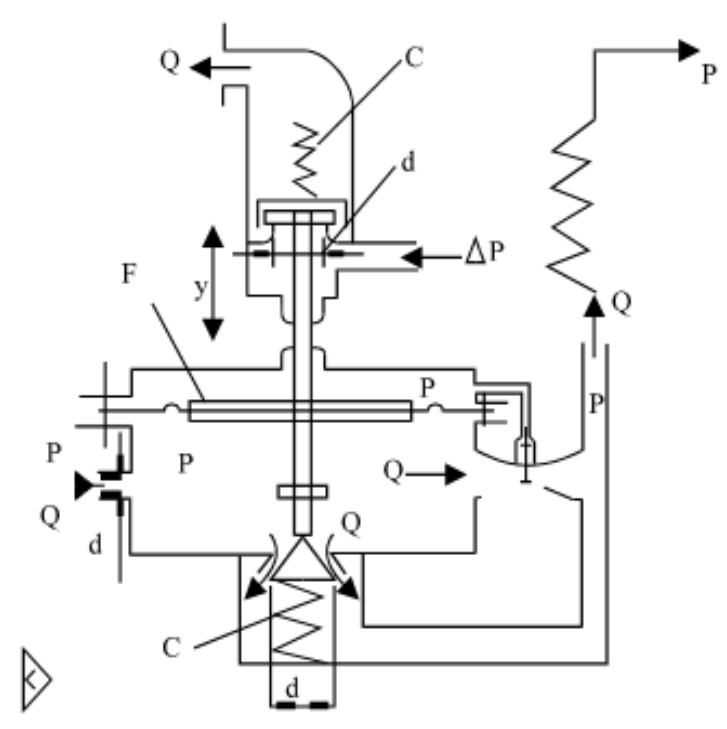

Fig. 2: The Arithmetic Sketch of the Control System with Side Element that Closes the Valve Openings

Graphic sketches of static qualities of the control system based on the above mentioned designs were obtained. Some of the most important qualities obtained are.

The quality (property) of consumption of the automatic hydraulic transformer $\left(\mathrm{G}_{\mathrm{B}}=\mathrm{f}\left(\mathrm{P}_{\mathrm{n}}\right)\right.$, the consumption property of the gas valve, which allows the flow of gas into the main burner $\left(\mathrm{Q}_{\mathrm{r}}=\mathrm{f}\left(\mathrm{P}_{\mathrm{n}}\right)\right.$, the relation between the change of water temperature and water pressure in the main line of water $t=f\left(P_{n}\right)$. Accordingly, hydraulic values $p n, Q_{B}, P_{r}, Q_{r}$ and geometric values $\mathrm{d}_{1}, \mathrm{~d}_{2}, \mathrm{~d}_{3}, \mathrm{~d}_{4}, \mathrm{~d}_{5}$ also mechanical values (solidity, former pressure on the spring which presses between the plate of the value and the seat of the valve) $C, Y_{o}$ all change.

The outcome of these analyses was that control system designed in accordance with the side elements, which close the valve opening Fig. 2 is distinguished for its static property $\Delta t=P_{n}$ which is reasonable when using water heaters for domestic purposes. This sketch was widely used in foreign designs. The consecutive connection sketch is distinguished for its high sensitivity, for in the case of consuming little amount of water, the water temperature reaches the boiling point. The sketch of side element which opens the valve opening is known for its insufficient sensitivity in all various cases of water consumption, which will not enable us get the level of water temperature required.

At the same time, it appeared that the property $\Delta t=$ f $\left(\mathrm{P}_{\mathrm{n}}\right)$ obtained by the control system (Fig. 2) Is not accepted in general since the hot water temperature is insufficient in the case of less consumption, except that the automatic hydraulic transformer designed in accordance with Fig. 2 is complicated and needs high level of preparation to make.

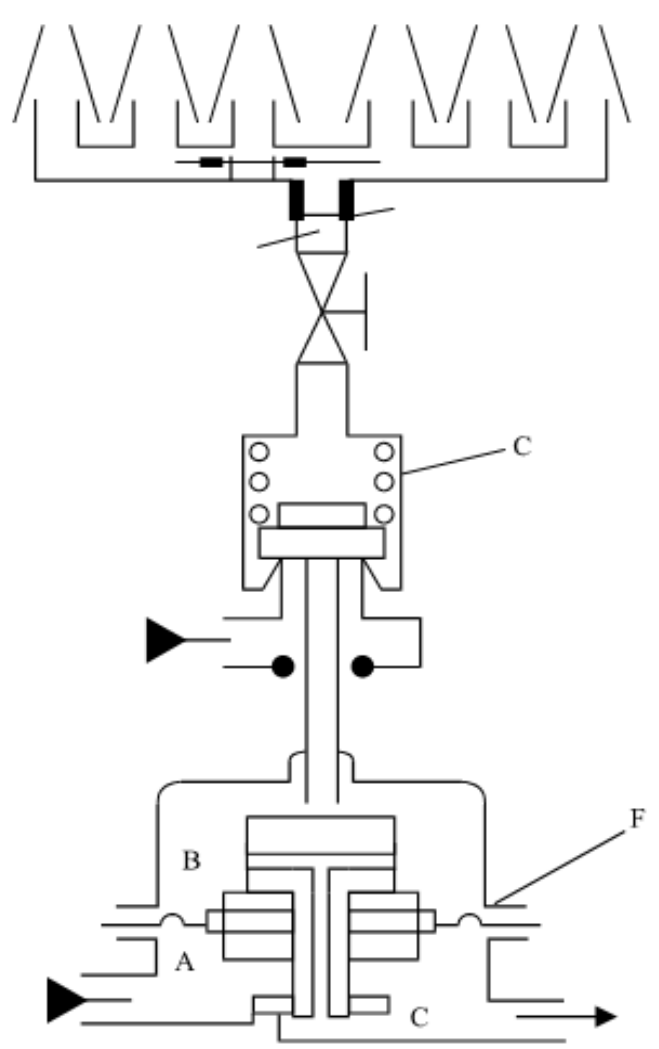

Fig. 3: The Arithmetic Sketch of the Control System with Circular Opening

Therefore, it is necessary to choose a reasonable sketch of a control system and choose reasonable values and measures for it.

The Automatic Hydraulic Transformer: The sketch of the automatic hydraulic transformer with a short circular opening with water circulation (Fig. 3).

This design provides us with the required properties for the relation between water consumption through the transformer and pressure in water pipes. $\mathrm{Q}_{\mathrm{B}}$ $=\mathrm{f}\left(\mathrm{P}_{\mathrm{n}}\right)$. It also saves water consumption through the transformer with the existence of pressure in the pipes ( $15 * 10^{5} \mathrm{~N} \mathrm{~m}^{-2}$ ). It also provides the least level of operation for the transformer in case there is pressure in the pipes $\left(15 * 10^{5} \mathrm{~N} \mathrm{~m}^{-2}\right)$. It also guarantees have obtained the highest degree for removing the hard medium of the surface $\left(5 * 10^{-3} \mathrm{~m}\right)$. Therefore, this design is distinguished for its simplicity and technique. In order to study the hydrodynamics of the water flow in the short circular opening, various references relevant to this subject were consulted. It was found that it is necessary to consider the leakage of the ideal liquid current with closed sides. This leakage occurs on a plate with specified or unspecified measures. This matter is considered continuous until a relation between the angle of the slope of the leaked current and the length of the split (Fig. 3) is obtained by solving the following equations:- 


$$
\begin{aligned}
& \left\{\begin{array}{l}
X=\frac{1}{V_{0}} \sqrt{\frac{\alpha-1}{\alpha+\beta}}\left[2 \sqrt{\beta} \operatorname{arctg}\left(\sqrt{\beta} \sqrt{\frac{e^{\varphi}+1}{e^{\varphi}-\beta}}\right)+\ln \left|\frac{1+\sqrt{\frac{e^{\varphi}+1}{e^{\varphi}-\beta}}}{1-\sqrt{\frac{e^{\varphi}+1}{e^{\varphi}-\beta}}}\right|\right]+\frac{1}{V_{0}} \sqrt{\frac{\beta+1}{\alpha+\beta}} \\
Y=\frac{1}{V_{0}} \sqrt{\frac{\alpha-1}{\alpha+\beta}}+\frac{1}{V_{0}} \sqrt{\frac{\beta+1}{\alpha+\beta}}\left[-\sqrt{\alpha} \ln \left|\frac{1-\sqrt{\alpha} \cdot \sqrt{\frac{e^{\varphi}+1}{e^{\varphi}+\alpha}}}{1+\sqrt{\alpha} \cdot \sqrt{\frac{e^{\varphi}+1}{e^{\varphi}+\alpha}}}\right|+\ln \left|\frac{1-\sqrt{\frac{e^{\varphi}+1}{e^{\varphi}+\alpha}}}{1+\sqrt{\frac{e^{\varphi}+1}{e^{\varphi}+\alpha}}}\right|\right]
\end{array}\right. \\
& K=\operatorname{tg} \theta=-\sqrt{\frac{\beta+1}{\alpha-1}}, \quad b_{2}=\frac{1}{V_{0}} \sqrt{\frac{\beta+1}{\alpha+\beta}\left[\begin{array}{l}
-\sqrt{\alpha \ln \left|\frac{1-\sqrt{\alpha}}{1+\sqrt{\alpha}}\right|+} \\
2 \sqrt{\beta} \operatorname{arctg} \sqrt{\beta}+ \\
\frac{\pi[\alpha-1+(\beta+1) \sqrt{\alpha}}{\alpha+1} \sqrt{\alpha-1}
\end{array}\right]} \\
& h 1=\frac{L \sqrt{\alpha+\beta}}{\sqrt{\alpha(\beta+1)+\sqrt{\beta(\alpha-1)}}}
\end{aligned}
$$

Physical models for the picture of the running water into the circular opening were taken on the air dynamics test platforms. Experiments were also carried out about the factor of consumption for the circular opening and by processing the results of the experiment and by the method of quadruplicating we can get a graph $\mu=f(\mathrm{Re})$ and the equation:

$$
\mu k l=0,08523868 * \operatorname{Pn}(5,80633428 * \mathrm{Re})
$$

After processing the mathematical models in the computer, the effects of the designing measures of the circular opening, the geometrical shapes of the split, the effect on the area of the surface on the property of consumption (Fig. 4) and the property of the lifting power of the automatic hydraulic transformer $\mathrm{P}=\left(\mathrm{Q}_{\mathrm{B}}\right)$ was studied and the transformer functioning in case of changing the measure of the diameter of the split and the effectiveness of the surface of the area were also studied.

Design, Selection and Logical Measures of the Gas Unit: When there is flow of cold water through the automatic hydraulic transformer, on the solid medium of the surface a power which shows a power that resists the power of the flexibility of the spring (C) and so the value of the flowing gas to the main burner opens (Fig. $3)$. The specific ring $\left(d_{4}\right)$ serves to get the needed pressure for gas $\left(\mathrm{P}_{\mathrm{r}}\right.$ in the collector through which across an opening with $\left(\mathrm{d}_{\mathrm{c}}\right)$ diameter the gas passes into the burner injector. For the injector burner and on the basis of the overflowing current equation a solution was obtained for selecting the diameter of the opening which provides the power of the required injected burner and a solution for the distance between the sector of the opening and the entrance of the injected burner and the selection of the diameter of the neck of the injected burner. By estimating the gas unit, the diameter of the specific ring was chosen on the basis of the following equations:

$$
\begin{aligned}
& \mu k=\mu c\left(1-e^{-A x}\right) \\
& \mathrm{P}_{2}=\frac{\left(1-\mathrm{e}^{-\frac{6 y}{d_{4}}}\right) \mathrm{F}_{4}^{2}\left(\mathrm{P}_{\text {system }}-\mathrm{P}_{3}\right)}{n^{2} F_{\mathrm{C}}^{2}} \\
& P_{3}=\frac{\mu_{C}^{2}\left(1-e^{-\frac{6 y}{d_{4}}}\right)^{2} F_{4}^{2} P_{C}+\frac{\mu_{w}^{2} F_{w}^{2}\left(1-e^{-\frac{6 y}{d_{4}}}\right)^{2} F_{4}^{2} P_{C}}{n^{2} F_{C}^{2}}}{\mu_{w}^{2} F_{w}^{2}+\frac{\mu_{w}^{2} F_{w}^{2}\left(1-e^{-\frac{6 y}{d_{4}}}\right)^{2} F_{4}^{2} P_{C}}{n^{2} F_{C}^{2}}+\mu_{C}^{2}\left(1-e^{-\frac{6 y}{d_{4}}}\right)^{2} F_{4}^{2}} \\
& Q_{k}=\mu_{C}\left(1-e^{-\frac{6 y}{d_{4}}}\right)^{2} \frac{\pi d_{4}^{2}}{4} \sqrt{\frac{2}{\rho_{\text {gas }}}} \sqrt{p_{\text {system }}-P_{4}} \\
& P_{4}=\frac{\mu_{C}^{2} F_{4}^{2}\left(1-e^{-\frac{6 y}{d_{4}}}\right)^{2} P s_{y s t e m}+\mu_{\text {chink }}^{2} F_{\text {chink }}^{2} P_{3}}{\mu_{\text {chink }}^{2} F_{\text {chink }}^{2}+\mu_{C}^{2} F_{4}^{2}\left(1-e^{-\frac{6 y}{d_{4}}}\right)^{2}}
\end{aligned}
$$


Table 1: Quantities Values

\begin{tabular}{llccc}
\hline № & Quantity & $\mathrm{Q}_{\mathrm{B}}=3.2 \times 10^{-5} \mathrm{~m}^{3} \mathrm{~s}^{-1}$ & $\mathrm{Q}_{\mathrm{B}}=4.53 \times 10^{-5} \mathrm{~m}^{3} \mathrm{~s}^{-1}$ & $\mathrm{Q}_{\mathrm{B}}=5.54 \times 10^{-5} \mathrm{~m}^{3} \mathrm{~s}^{-1}$ \\
\hline 1 & $\mathrm{dc}(\mathrm{mm})$ & 1.25 & 1.26 & 1.27 \\
2 & $\mathrm{dw}(\mathrm{mm})$ & 3.75 & 3.75 & 3.77 \\
3 & $\mathrm{C}\left(\mathrm{N} \mathrm{m}^{-1}\right)$ & $9.82 \times 10^{3}$ & $9.82 \times 10^{3}$ & $9.82 \times 10^{3}$ \\
4 & $\mathrm{y}_{0}(\mathrm{~mm})$ & 3.79 & 3.79 & 3.79 \\
\hline
\end{tabular}

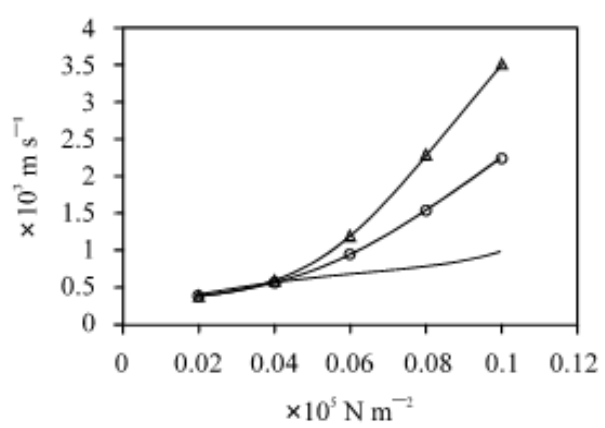

Fig. 4: Consumption Property of the Circular Opening with an Approximating Cone $\left(1-\alpha=0^{0} 2-\alpha=5^{0}\right.$ $3-\alpha=10^{0}$ )
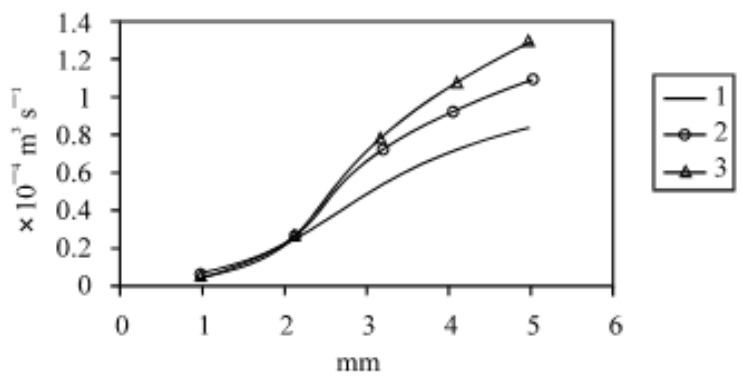

Fig. 5: The Property of Manual Control Effect on the Gas Unit $\left(1-\mathrm{P}_{\mathrm{w}}=25 \mathrm{~N} 2-\mathrm{P}_{\mathrm{w}}=30 \mathrm{~N} 3-\mathrm{P}_{\mathrm{w}}=35 \mathrm{~N}\right)$

With the equations of the overflowing current, graphs showing the relation between gas consumption through the gas unit and measurers of geometrical unit and values of the gas dynamics. By analyzing these graphs we can select the proper measures for designing the gas unit in a specified system of work. A sketch for the structure of the gas regulator was designed in the main burner by inserting manual control element through the valve opening on the side surface of the cylinder with thin walls. Inserting such a manual element saves an effective control power for the gas consumption in the main burner (Fig. 5).

The fourth-main title includes an analysis of the function of the control unit and the choice of its real values.

Mathematical Model: The mathematical models for the control unit are placed in a form of equations:

$Q_{B}=\mu_{K l} f_{K L} \sqrt{\frac{2}{\rho_{B}}} \sqrt{P_{a}-P_{c}}$

$$
P=\left(P_{a}-P_{B}\right) F_{m}=\left(y+y_{0}\right) C
$$

$Q_{k}=\mu_{C}\left(1-e^{-\frac{6 y}{d_{4}}}\right)^{2} \frac{\pi d_{4}^{2}}{4} \times$

$$
\sqrt{\frac{2}{\rho_{\text {gas }}}} \sqrt{p_{\text {sssem }}-P_{4}}
$$

$Q_{\text {chink }}=\mu_{\text {chink }} \sqrt{\frac{2}{\rho_{\text {gas }}}} \sqrt{P_{4}-P_{3}}$

$F_{\text {chink }}=\frac{Z}{6 S}\left(3 Z^{2}-4 S^{2}\right)$

$Q_{\text {washer }}=\mu_{\text {washer }} \frac{\pi d_{\text {asher }}^{2}}{4} \sqrt{\frac{2}{\rho_{\text {gas }}}} \sqrt{p_{\text {system }}-P_{4}}$

$\sum_{i=1}^{n} Q_{C}=n \mu_{C}{ }^{2} \frac{\pi d_{C}^{2}}{4} \sqrt{\frac{2}{\rho_{\text {gas }}}} \sqrt{p_{2}}$

$\Delta t=\frac{Q_{k} K_{4} \eta_{T}}{Q_{B} C_{B} \rho_{B}}$

The common solution of the equations (10-17) allows us to get the main static qualities of the control unit $Q_{R}=f\left(Q_{B}\right)$ and the water heater $A_{t}=f\left(Q_{B}\right)$. Necessary analyses were carried out to explain the designed and mechanical values of the control unit of the following static qualities: The geometrical sector of the valve opening in the course of the manual control of the gas flow, the diameter of the valve base, the diameter of the specified ring, diameter of the opening of the injected burner, solidity and pre- pressure on the valve spring. Graphs were introduced to explain the effect those values on the function of the gas unit. An analysis of the speed of the function of the control unit was carried out by solving the following equations:

$W(S)=\frac{\Delta t(S)}{Q_{R}(S}=\frac{\eta_{T} d Q_{R} K_{4} /\left(\rho_{B} d Q_{R} C_{B}\right)}{T_{S}+1}$

$T=\frac{M_{k}}{\rho_{B} Q_{B} C_{B}}$ 


$$
y=\sqrt{\frac{2\left(P_{B}-P_{C}\right) d_{\text {Canel }}^{5}}{\lambda L_{\text {chanel }} d_{m}^{4} \rho_{B}}}
$$

It was found that an effective control of the function time of the control system is possible by changing the diameter of the course of the split (Fig. 6). In studying the experiment on the heater low capacity gaseous flowing water, it was found that the practical results were identical to the arithmetic results ${ }^{[4]}$.

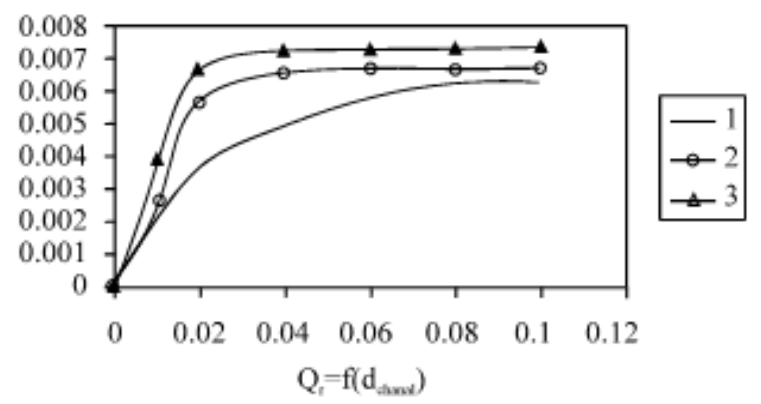

Fig. 6: The Effect of the Diameter of the Ant-Vibration Sector on the Dynamic of the Control System $\left(1-\mathrm{d}_{\text {channel }}=1.10^{-3} \mathrm{~m}^{2} 2-\mathrm{d}_{\text {channel }}=1,5.10^{-3} \mathrm{~m}^{2} 3\right.$ $\mathrm{d}_{\text {channel }}=2.10^{-3} \mathrm{~m}^{2}$ )

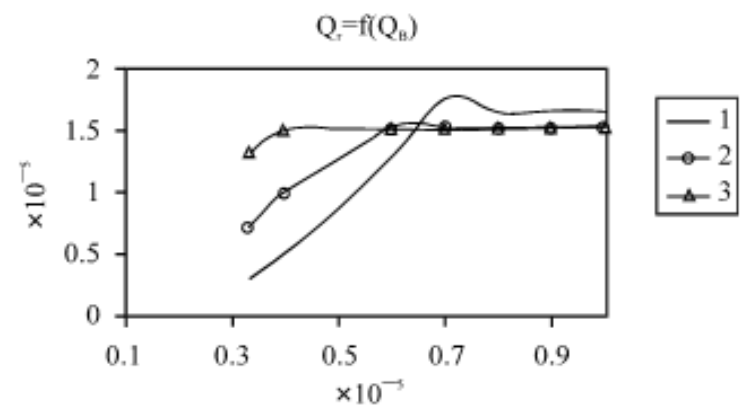

Fig. 7: Comparison Qualities between the Suggested Control System and the Well Known One (1Permanent section, 2-Variable section 3- Sketch of Fig. 2)

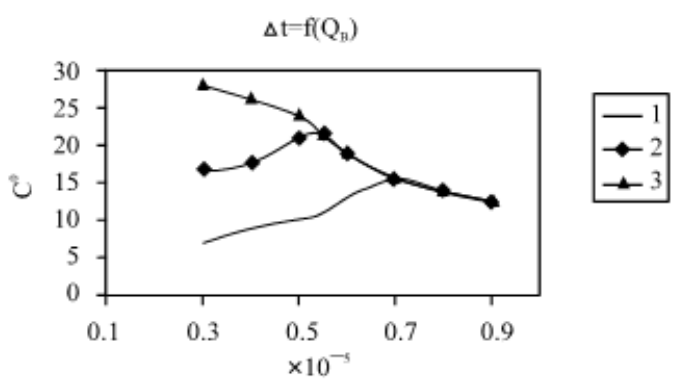

Fig. 8: The Comparison Qualities between the Suggested and what is Known Regarding Low Capacity Gaseous Flowing Water Heaters (1Permanent Section, 2-Variable Section 3Sketch of Fig. 2)
The choice of logical values of the control system was based on getting hot water for low consumption and therefore getting the required water temperature, getting a minimum change in water temperature when there is a change in water pressure, the function of the automatic hydraulic transformer whenever there is a demand for a minimum pressure in the water pipes and closing the valve when water consumption is stopped. The solution for this problem happened by choosing the diameter of the opening, the diameter of the specified ring, solidity and pre- pressure on the spring and the size of the valve openings in the press ${ }^{[4,5]}$. The study of the practical and experimental results allows us to obtain realistic values of the control system in the various capacities gaseous flowing water heaters.

A comparison was made between the static properties of the control system design by the author and a well- known control system (Fig. 7, 8), it was found that the control system suggested by the author widens the scope of control of hot water temperature in case of low consumption (curves 1,2). In this case and by choosing the cylinder- shaped part of the split we can easily get the required properties ${ }^{[4]}$ :

$\mathrm{Q}_{\mathrm{r}}=\mathrm{f}\left(\mathrm{Q}_{\mathrm{B}}\right)$ and $\mathrm{T}=\mathrm{f}\left(\mathrm{Q}_{\mathrm{B}}\right)$

\section{CONCLUSION}

The new in the scientific work can be summed up as follows:

* An analysis of the control system and the automatic hydraulic transformer of low capacity gaseous flowing water heaters was made. It was found that the control system based on the automatic hydraulic transformer with side openings and side element that closes the valve opening is characterized for being accepted by the user (customer), $Q_{r}=\left(Q_{B}\right), A_{t}=f\left(Q_{B}\right)$, therefore, this sketch has been used remarkably.

* However, the sketch is not capable of achieving great and simple capacity to control water temperature in low consumption. This sketch is characterized for its complex design and technique.

* A sketch for an automatic hydraulic transformer and control system was suggested to cover the defect mentioned above.

* Mathematical models of the fluid dynamics of the water flow in the circular opening on the basis of the identical connection theory were made. The sketches of the leakage of the ideal liquid current were treated to a plate with or without limited measurement in order to identify the degree of current distortion in the circular opening.

* Studies of and experiments were carried out on the static properties of the automatic hydraulic transformer. 
* The realistic sketch of the gas unit was chosen on the basis of the injected burner: an analysis of the drainage properties of the opening unit of the main burner was done: the diameter of the mouth of the injected burner and its neck and the diameter of the specified ring was decided in accordance with the capacity of the heater. The property of drainage in the valve which regulates the flow of gas into the main burner calculated and the basis of selecting the geometrical measures of this valve were set. A sketch of the control unit that regulates the flow of gas into the main burner was also set. The bases of the real form of the valve openings in the control unit system of the flowing gas were set.

* An analysis and a study of the effect of the fluid dynamics and the mechanical values of the control unit in order to set the basis of selecting the real values of the control system which allows to achieve the required properties $\Delta \mathrm{t}=\mathrm{f}\left(\mathrm{Q}_{\mathrm{B}}\right)$. The function speed of the control system and the methods of affecting this speed were tested.

* A comparison between the static qualities of the suggested control system and the well-known system was made. It was found that the suggested control system with its simple design and technique has a better property $\Delta \mathrm{t}=\mathrm{f}\left(\mathrm{Q}_{\mathrm{B}}\right)$ compared with the known systems.

\section{REFERENCES}

1. Proceedings of the Seventy-Eighth GPA Annual Convention. Nashville, TN: Gas Processors Association, 1999: 46-52. 8th Annual Energy Week Conference: 1997.

2. Layne, R., 1986. "Never-Ending Hot Water and Energy Savings, Too" Popular Science, (228:4), pp: 106-08, 150-51.

3. Wagner, J., 1997. On-demand Water Heaters. J. Light Construction, 15: 51-54.

4. Report Number PB-87200390, 1987. Performance of Instantaneous Gas-Fired Water Heaters. National Bureau of Standards, www.ntis.gov, pp: 66.

5. Wiehagen, J. and J.L. Sikora, 2003. Performance Comparison Residential Hot Water Systems. Reports of the NAHB Res. Center Upper Marlboro, Maryland and the National Renewable Energy laboratory Colorado, pp: 160. 